\title{
Introduction
}

In a provocative article in the American Economic Review titled 'The age of Schumpeter' the noted German economist, Herbert Giersch, specified 10 basic postulates for a post-Schumpeterian paradigm. The first of these was:

The approach is micro rather than macro, socioeconomic (if not socioecological) rather than mechanistic. In the spirit of Schumpeter's 'methodological individualism' it concentrates on processes rather than outcomes, on voluntarism rather than determinism. Being addressed to current world economic development, it stresses relevance rather than rigor, movement rather than static optimality. (Giersch, 1984: 105)

This book embodies the spirit of this postulate. The theoretical development presented here seeks to provide valid microfoundations for an economics in which Schumpeterian perspectives on innovation, competition and growth are integral, yet consistent with recent evidence from evolutionary economics on the dynamics of markets and industries as well as with recent developments in behavioral economics on human decisionmaking. The empirical evidence for the microfoundations comes from a cognitive science based study of entrepreneurial expertise using thinkaloud verbal protocols. The evidence points to an alternative logic of decision-making under uncertainty that not only embodies the spirit of the postulate stated above but also clearly contrasts with mainstream models based on a causal logic.

Causal logic provides useful decision criteria to achieve given goals subject to environmental selection in the face of an uncertain future. Effectual logic provides useful design principles for transforming extant environments into new futures in the face of ambiguous goals. An entirely causal presentation of an effectual logic would be absurd. Hence I present empirical evidence as part of an ongoing story of research; and I use reallife examples as illustrations of what could be rather than as claims to truth about what actually is.

The book is divided into four parts:

- The first part tells the story of my empirical work in developing a baseline model of entrepreneurial expertise, which I have dubbed effectuation - to signify the inverse of causation. 
- The second fleshes out the empirically derived skeleton into a complete theoretical logic and develops predictive relationships between its principles and entrepreneurial performance.

- The third part examines what an effectual logic implies for selected issues relevant to the economics of business and entrepreneurship particularly:

- Herbert Simon's ideas in Sciences of the Artificial

- Current debates in strategic management and entrepreneurship

- Milton Friedman's famous essay on positive economics

- Entrepreneurship outside the for-profit sector

Each of these implications is meant to spur readers to consider how the ideas laid out in the first two parts could be used. I have unashamedly made speculative leaps, trusting that future work will fill in the gaps.

- The fourth and final part of the book outlines applications to practice, pedagogy and policy, and explores possibilities for future research. Included in this part are three important pieces by others who are developing their own research agendas based on the ideas in the book.

\section{CHAPTER SUMMARIES}

\section{Chapter 1 What I Set Out to Study and Why}

Chapter 1 is an outline of the study - from motivation to results. Here I lay out key research issues of interest to any scholar of entrepreneurship and explain why and how the expertise perspective from cognitive science would be useful. In a nutshell, I created a 17-page problem set of 10 typical decisions in a startup firm and had a reasonably representative sample of 27 expert entrepreneurs think aloud continuously as they solved the problems. The think-aloud protocols were collected on tape and the transcriptions of the tape formed the primary data for the study. I end the chapter with a summary of major findings.

\section{Chapter 2 What I Found and How}

Here I describe the research design in detail and develop the central hypothesis to be tested through quantitative analysis of the data I collected. I also describe how I analysed the data and then move on to qualitative analyses of the contents of the think-aloud protocols. Then I outline the elements of entrepreneurial expertise directly induced from the data. These comprise the bare bones of the effectual logic to be fleshed out in later chapters. 


\section{Chapter 3 Interpreting What I Found}

In this chapter, I describe how I began interpreting the induced elements and their implications for further work. I also describe a key transition that occurred in my own understanding at this point. This had to do with doubts about a purely positivist research agenda and the lure of a more pragmatist approach. From this point on, the book begins to develop effectuation as a logic of entrepreneurial action that has both theoretical and methodological implications for entrepreneurship research, rather than as a theory to be pitted against extant theories. This does not mean, however, that I am indifferent to ongoing work to test the empirical validity of ideas in the book. In fact, I outline a number of completed and ongoing studies that are engaged in exactly that enterprise. But the rest of this book is devoted to digging into the details of an effectual logic and carefully connecting them with a variety of key issues of import to those interested in entrepreneurship.

\section{Chapter 4 Understanding Effectuation - Problem Space and Solution Principles}

Here I describe the static aspects of an effectual logic and clarify each in detail. In particular, I delve into the three dimensions of the problem space in which it makes sense to employ an effectual logic and work out in depth each of the five solution principles of effectuation.

\section{Chapter 5 Understanding Effectuation - Dynamics of the Effectual Process}

Chapter 5 contains the core of an effectual logic. Here I trace out in detail how the principles of effectuation can be used in a dynamic and interactive process that creates new markets. In particular, I argue that new-market creation is not always a search and selection process in some theoretical space of all possible markets; instead, it is more likely a transformation of extant realities into new possibilities. In analysing the dynamics of an effectual logic, I confront a powerful tension at the heart of our ideas about how new markets come to be; inside that tension lies a deeper tension identified by the pragmatist philosopher Nelson Goodman. Some readers might find the philosophical baggage rather cumbersome; I hasten to affirm that you do not have to 'buy' that baggage in order to grapple with the core ideas here.

\section{Chapter 6 Relating Effectuation to Performance}

We return to empirical matters in this chapter, where I work out testable predictions from effectuation with regard to entrepreneurial performance. 
The key insight encapsulated in the predictions is the separation of firm performance from the performance of the entrepreneur. Driven by that insight, I trace performance implications of an effectual logic over the life cycles of firms as well as over the careers of entrepreneurs. This allows me to tackle the idea that firm failures can be vital inputs in entrepreneurial success - an idea that overturns the conventional wisdom about the explanatory power of human capital in firm performance.

Chapters 7 through 10 are clearly not everyone's cup of tea - and I invite you to skip the ones that may be too far from your interests.

\section{Chapter 7 Entrepreneurship as a Science of the Artificial}

In this chapter, I explore connections between effectuation and the ideas laid out by Herbert Simon in his book Sciences of the Artificial, where, with characteristic flair, Simon introduced a new class of sciences. The sciences of the artificial differ both from natural and social sciences, because they incorporate design - the intentions and purposes of an intelligent designer. I propose in this chapter that entrepreneurship be studied as a science of the artificial and focus especially on Simon's elucidation of near-decomposability as a ubiquitous feature of the architecture of complexity. This is the only chapter that has a touch of formal analysis.

\section{Chapter 8 Competitive Advantages and Entrepreneurial Opportunities}

In Chapter 8, I connect ideas from effectuation to current debates in strategic management and entrepreneurship. Sustainable competitive advantage has for a long time been the holy grail of strategic management; and opportunities have become a recent obsession in entrepreneurship. An effectual logic has relevant contributions to both - and I explore them in this chapter. Effectuation emphasizes the role of exit as a strategic tool. This is not a well-studied area and merits further attention, particularly given the substantial role of entrepreneurship both as cause and effect of strategic exit for individuals as well as for firms. Similarly, effectuation also highlights a key underresearched problem in entrepreneurship - namely, the origin of opportunities. Current theories appear to assume that opportunities exist and that the entrepreneurial function consists in their discovery. But the ideas in this book suggest that opportunities themselves originate through the effectual process. This sets up a curious puzzle as to when and under what circumstances we need to take opportunities as given. 


\section{Chapter 9 Philosophy and Methodology of Effectual Economics}

This is a rather ambitious chapter that attempts the first steps toward building an effectual economics. I tentatively think through the philosophical basis for such an enterprise and briefly sketch an overall methodology. In this I take my cues from Milton Friedman's famous essay on the methodology of positive economics. I strive to keep the argument very close to his and point out several exciting possibilities (most of them far from being completely worked out) for a new branch of economics that could be built on the microfoundations of an effectual logic.

\section{Chapter 10 Markets in Human Hope}

This chapter is very close to my heart and comes from my puzzling over the reasons (or rather the lack of economic reasons) for distinguishing forprofit ventures from other types of ventures. Entrepreneurs build all types of ventures - for-profit, non-profit, social and hybrid. And an effectual logic is useful in all these varieties of ventures. Yet there is an artificial divide in how they can fund these enterprises and what regulatory provisions they need to contend with in building them. This chapter is a call to arms to overcome this superfluous separation so that individuals and societies can make better use of the entrepreneurial method in unleashing human potential to generate and attain novelty in ends as well as means.

\section{Chapter 11 Teaching Effectuation}

Here I share my experiences teaching effectuation. To the best of my knowledge, at least 15 business schools have incorporated effectuation to some degree in their entrepreneurship curricula. But clearly there is more work to be done, and I examine the potential for developing a full-fledged course on effectual logic.

\section{Chapter 12 Research Works-in-Progress}

This chapter is written by three of my collaborators, Nicholas Dew, Stuart Read and Robert Wiltbank. They report in their own words how they are extending the ideas related to effectuation. Dew explores effectuation in the context of the evolution of new technologies and new industries through an in-depth account of the Radio Frequency Identity (RFID) industry. Read presents a meta-analysis of extant empirical work in entrepreneurship to find out what we already know about the relationship of an effectual logic to new-venture performance. Wiltbank shows the impact of using 
strategies of non-predictive control on the performance of angel investors. All three of these individuals have contributed in numerous ways to this book as a whole - and it is my honor and privilege to have them speak about their work in their own words.

\section{Chapter 13 New Research Ventures}

The last chapter looks back at the book to identify things I have not done or not done well so far. It lists empirical questions yet to be investigated, identifies major unresolved tensions in ongoing research, and outlines possibilities for future work. 